\title{
ProANP as a screening biomarker for hypertrophic cardiomyopathy in Maine coon cats
}

\author{
M. Parzeniecka-Jaworska, M. Garncarz, W. Kluciński \\ Department of Pathology and Veterinary Diagnostics, Faculty of Veterinary Medicine, \\ Warsaw University of Life Sciences, Nowoursynowska 159c, Warsaw, Poland
}

\begin{abstract}
The aim of this study was to determine if atrial natriuretic peptide can be used as an early screening tool for hypertrophic cardiomyopathy in Maine coon cats.

Animals: The study was performed in 43 Maine coon cats of both sexes, aged 11 to 92 months. Clinical and echocardiographic examinations were done and proANP serum concentrations were measured every three months over a period of one year (each cat had a total of five examinations). Cats were divided into 3 groups based on echocardiographic results: group 1 - healthy cats, group 2 - cats with unequivocal hypertrophic cardiomyopathy results, group 3 - cats with HCM. The study showed that the concentration of atrial natriuretic peptide correlates with the severity of HCM. A significant increase in serum concentration of this peptide was observed in cats from group 3, but it did not differ significantly between cats from group 2 and the healthy animals $(p>0.05)$. A correlation was also found between proANP and age of the cats $(p<0.01, r=0.5578)$ as well as between the ejection fraction $(p=0.0285, r=0.5305)$ and end-systolic left ventricular diameter $(p=0.05, r=0.48)$ in the affected animals. Atrial natriuretic peptide may be used to help in the diagnosis of advanced stages of HCM in Maine coon cats. Cats with high levels of proANP should be assigned to echocardiographic studies to confirm the disease.
\end{abstract}

Key words: cat, cardiac diseases, natriuretic peptide

Abbreviations:

ANP - atrial natriuretic peptide

Ao - aortic diameter

EF - ejection fraction

EPSS - end-point to septal separation

FS - fractional shortening

HCM - hypertrophic cardiomyopathy

IVSd - intraventricular septum diastolic diameter
IVSs - intraventricular septum systolic diameter

LA - atrial diameter

LVDd - left ventricular diastolic diameter

LVDs - left ventricular systolic diameter

LVWd - left ventricular wall diastolic diameter

LVWs - left ventricular wall systolic diameter

proANP - pro-atrial natriuretic peptide

Correspondence to: M. Parzeniecka-Jaworska, e-mail: marta_parzeniecka@sggw.pl 


\section{Introduction}

Maine coon cats are one of the most popular breed of cats in the world. As recently revealed (Gough and Thomas 2004) they are predisposed to hypertrophic cardiomyopathy (HCM), a hereditary disease confirmed to be an autosomal dominant trait. Hypertrophic cardiomyopathy is the most common cardiac disease in cats. Kittleson (1998) has shown that the disease is characterized by primary concentric hypertrophy of the left ventricle. Most cats with HCM do not have clinical signs until the disease becomes severe. One of the major complications of HCM is arterial thromboembolism. Ware (2007) and Jandrey (2012) have shown that it can occur without any other sings. As recently revealed (Kittleson 1998) the diagnosis of HCM is made on the basis of an echocardiographic examination. However, because this is a costly exam, not all breeders are willing to invest in this type of screening test. Usually owners decide to have their cats examined echocardiographically once clinical signs of HCM are apparent and the disease is severe. Screening tests for the MyBPC-3 mutation are possible, albeit costly. Meurs et al (2009) have shown that there are standard tests which can detect two mutations of this gene. It is known (Kittleson et al. 1999) that HCM in Maine coon cats is similar to familial HCM in people. In humans, to date over 450 mutations have been identified (Sampedrans 2009). For this reason a diagnosis of HCM should not be made solely based on genetic tests. Because of these problems and the fact that the disease can be lethal, early recognition of affected cats is necessary to extend patients' lives.

Biomarkers, such as atrial natriuretic peptide (ANP), are playing an increasingly important role in the diagnosis of heart disease, especially in its early recognition. Atrial natriuretic peptide is synthesized, stored and released into circulation by atrial myocytes but also in small amounts by ventricular myocytes and brain cells. As recently revealed (Müller 2006, Boswood 2009, Conolly 2010, Kołodziejska et al. 2010, Zimmering et al. 2010) atrial natriuretic peptide plays a role in pressure homeostasis by counteracting the renin-angiotensin-aldosterone system. Atrial natriuretic peptide causes suppression of renin action, which leads to suppression of aldosterone action and distribution of argininovasopressin. Atrial natriuretic peptide induces diuresis, natriuresis and peripheral vasodilation, which result in a decrease in atrial blood pressure and cardiac overload. Pro-ANP has a longer half-life and is more stable in serum, and therefore it is the concentrations of proANP that is determined.

When determining serum proANP in cats we should remember that this marker is also increased in cats with respiratory distress (Connolly et al. 2009, Borgeat et al. 2015), although concentrations are significantly lower than those found in the animals with respiratory distress secondary to heart failure. Increased proANP levels have also been shown in renal insufficiency associated with hypertension (Lalor et al. 2009), while no statistically significant increases in concentrations of proANP were observed in cats with hyperthyroidism compared with those found in the healthy control animals (Menaut et al. 2012).

\section{Materials and Methods}

A prospective study and data analysis were carried out on cats submitted to the Cardiology Service of the Small Animal Clinic, Faculty of Veterinary Medicine, Warsaw University of Life Sciences (Poland). This study complies with national and institutional guidelines on the use of animals in clinical research according to the Polish legal act concerning experiments performed on animals from January 21st, 2005. Since the blood for proANP analyses was taken during a routine veterinary examination and in accordance with the above mentioned legal act, a written ethical approval from the Local Ethics Committee before beginning of the study was not necessary.

The study was performed on 43 Maine coon cats of both sexes, aged 11 to 92 months. Each cat was examined at day 0 , then every three months during a year for a total of 5 examinations. One cat had only 3 examinations because of cardiac death and 29 cats had only 4 examinations because of pregnancy. A clinical examination, blood morphology and biochemistry analysis, serum T4 levels, and arterial blood pressure (Parks 811-B) were evaluated in each cat. Cats initially diagnosed with hyperthyroidism, hypertension and/or kidney disease were excluded from further studies, thereby eliminating cases of secondary myocardial hypertrophy.

An electrocardiographic (ECG) exam (BTL- 08 $\mathrm{MD})$ in right lateral recumbency and a transthoracic echocardiographic (TTE) (Aloka 4000, 5-7.5 sector transducer) exam were performed during each visit. All examinations were performed at rest without pharmacological restraint. The examinations were performed and interpreted personally by doctor working in the Cardiology Service. Examinations were performed according to published norms. In some cases the examination was carried out on cats in standing position to minimize stress. Standard M-mode measurements included left ventricular wall thickness in diastole (IVSd, LVWd) and systole (IVSs, LVWs), left ventricular diastolic and systolic diameter (LVDd, LVDs), end-point to septal separation (EPSS), 
Table 1. Characteristics of three groups of Maine Coon cats.

\begin{tabular}{cccc}
\hline Group & Number of cats & Number of examinations & Age (months) \\
\hline Group 1 & 21 & 91 & $11-50$ \\
\hline Group 2 & 18 & 69 & $25-92$ \\
\hline Group 3 & 4 & 17 & $21-79$ \\
\hline
\end{tabular}

Group 1 - healthy cats, Group 2 - unequivocal, group 3 - cats with left ventricular hypertrophy

Table 2. Characteristics of subgroups divided according to age.

\begin{tabular}{ccccc}
\hline Subgroups & Age (months) & $\begin{array}{c}\text { Number of examination } \\
\text { in group 1 }\end{array}$ & $\begin{array}{c}\text { Number of examination } \\
\text { in group 2 }\end{array}$ & $\begin{array}{c}\text { Number of examination } \\
\text { in group 3 }\end{array}$ \\
\hline A & $<24$ & 27 & 0 & 2 \\
\hline B & $25-28$ & 16 & 2 & 2 \\
\hline C & $29-32$ & 17 & 1 & 3 \\
\hline D & $33-36$ & 11 & 4 & 10 \\
\hline E & $37-40$ & 11 & 6 & 1 \\
\hline F & $41-44$ & 5 & 46 & 6 \\
\hline G & $>45$ & 4 & & \\
\hline
\end{tabular}

Table 3. Characteristics of subgroups divided according to body weight.

\begin{tabular}{ccccc}
\hline Subgroups & Body weight $(\mathrm{kg})$ & $\begin{array}{c}\text { Number of examination } \\
\text { in group 1 }\end{array}$ & $\begin{array}{c}\text { Number of examination } \\
\text { in group 2 }\end{array}$ & $\begin{array}{c}\text { Number of examination } \\
\text { in group 3 }\end{array}$ \\
\hline A & $4.0-5.0$ & 13 & 13 & 0 \\
\hline B & $5.1-6.0$ & 24 & 32 & 5 \\
\hline C & $6.1-7.0$ & 23 & 5 & 0 \\
\hline D & $7.1-8.0$ & 19 & 9 & 7 \\
\hline E & $>8.1$ & 12 & 10 & 5 \\
\hline
\end{tabular}

fractional shortening (FS) and ejection fraction (EF). Standard two-dimentional measurements included aortic diameter (Ao), left atrial diameter (LA), left ventricular wall thickness in diastole (IVSd, LVWd) and systole (IVSs, LVWs) and left ventricular lumen in diastole and systole (LVDd, LVDs). During each of the examinations in each cat, the concentration of serum proANP was measured. Once blood samples were taken, they were immediately spinned down and the serum was frozen at $-20^{\circ} \mathrm{C}$. Samples were stored for up to 4-6 months, after which an ELISA test was performed using human proANP kits (Biomedica). As shown in previous studies (MacLean et al. 2006) it is known that we can use human tests to determine the concentration of pro-ANP. This results from the fact that human and feline NT-proANP amino acids 10-19 and 85-90 are identical.

On the basis of echocardiography the cats were divided into 3 groups (Table 1). Group 1 encompassed cats with no hypertrophy (healthy), group 2 - unequivocal cats (left ventricular wall $0.55-0.60 \mathrm{~cm}$ in diastole and/or papillary muscle hypertrophy), and group 3 - cats with left ventricular hypertrophy $(>0.60$ $\mathrm{cm})$. In addition, each group was divided into subgroups according to age (Table 2) and body weight (Table 3).

The values were given as a mean with standard deviation and the results were statistically analyzed using the Statistical Graphic System v.4.1 program. Echocardiographic measurements and serum atrial natriuretic peptide concentrations were analyzed by repeated measures analysis of variance (ANOVA). Correlation coefficient and regression were calculated between serum proANP concentrations and echocardiographic measurements. A value of $\mathrm{p}<0.05$ was considered statistically significant.

\section{Results}

A total of 177 examinations were performed on 43 Maine coon cats. Table 4 shows information acquired 
Table 4. Clinical signs based on history in 43 Maine Coon cats.

\begin{tabular}{lccc}
\hline \multirow{2}{*}{ Clinical signs } & \multicolumn{2}{c}{ Group } & 3 \\
\cline { 2 - 5 } & 1 & 2 & $(\mathrm{n}=4$ cats $)$ \\
\hline Exercise intolerance $(\%)$ & $(\mathrm{n}=21$ cats $)$ & 0 & 50 \\
\hline Cough $(\%)$ & 0 & 0 & 0 \\
\hline Dyspnoe $(\%)$ & 0 & 0 & 25 \\
\hline Syncope $(\%)$ & 0 & 0 & 0 \\
\hline
\end{tabular}

Group 1 - healthy cats, Group 2 - unequivocal, group 3 - cats with left ventricular hypertrophy

Table 5. Data of physical examination In 43 Maine Coon cats.

\begin{tabular}{lccc}
\hline \multirow{2}{*}{ Physical examination } & \multicolumn{2}{c}{ Group } \\
\cline { 2 - 4 } & $\begin{array}{c}1 \\
(\mathrm{n}=21 \text { cats })\end{array}$ & $\begin{array}{c}2 \\
(\mathrm{n}=18 \text { cats })\end{array}$ & $\begin{array}{c}3 \\
(\mathrm{n}=4 \text { cats })\end{array}$ \\
\hline Heart rate $(\mathrm{bpm})$ & $195.36 \pm 24.71$ & $193.36 \pm 15.31$ & $184.12 \pm 27.61$ \\
\hline Heart murmur $(\%)$ & 0 & 0 & 50 \\
\hline Gallop sound $(\%)$ & 0 & 0 & 50 \\
\hline Systolic blood pressure $(\mathrm{mmHg})$ & $109.92 \pm 17.01$ & $112.80- \pm 9.13$ & $109.02 \pm 18.40$
\end{tabular}

Group 1 - healthy cats, Group 2 - unequivocal, group 3 - cats with left ventricular hypertrophy

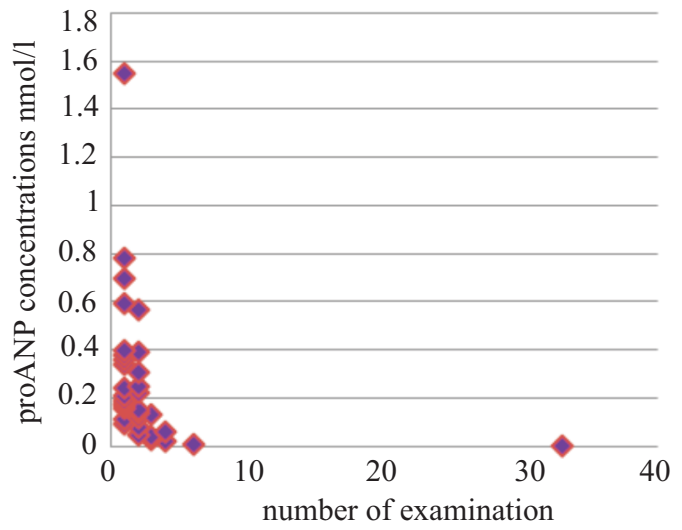

ANP concentrations in healthy cats from group 1

Fig. 1. proANP concentrations in the healthy cats from group 1.

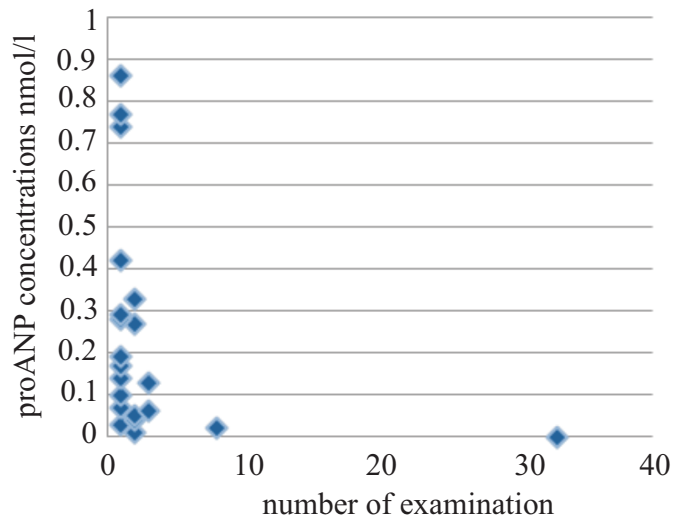

ANP concentrations in cats from group 2

Fig. 2. proANP concentrations in the cats from group 2. 


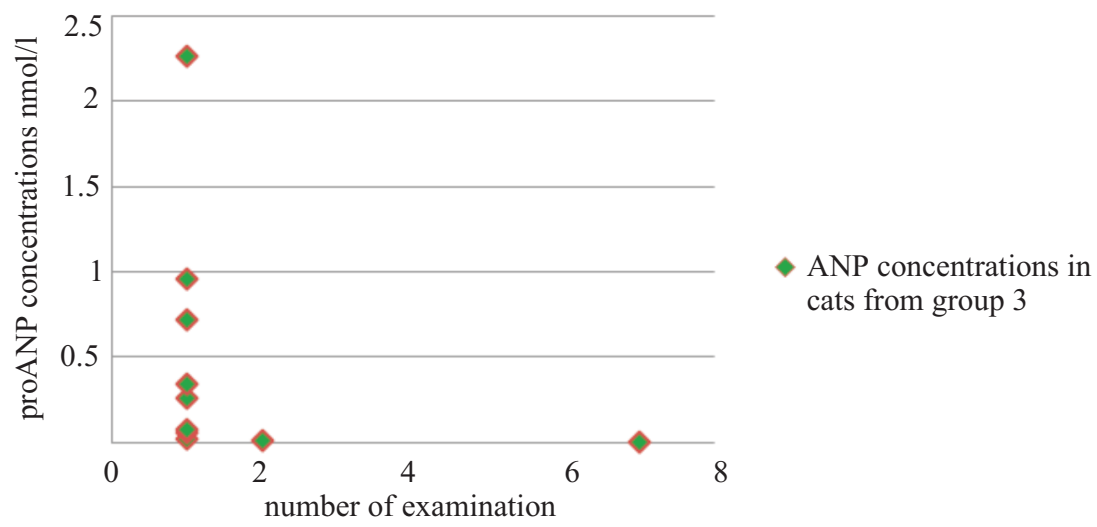

Fig. 3. proANP concentrations in the cats from group 3.

Simple Regression - IVSd 2D vs. age (months)

Plot of Fitted Model

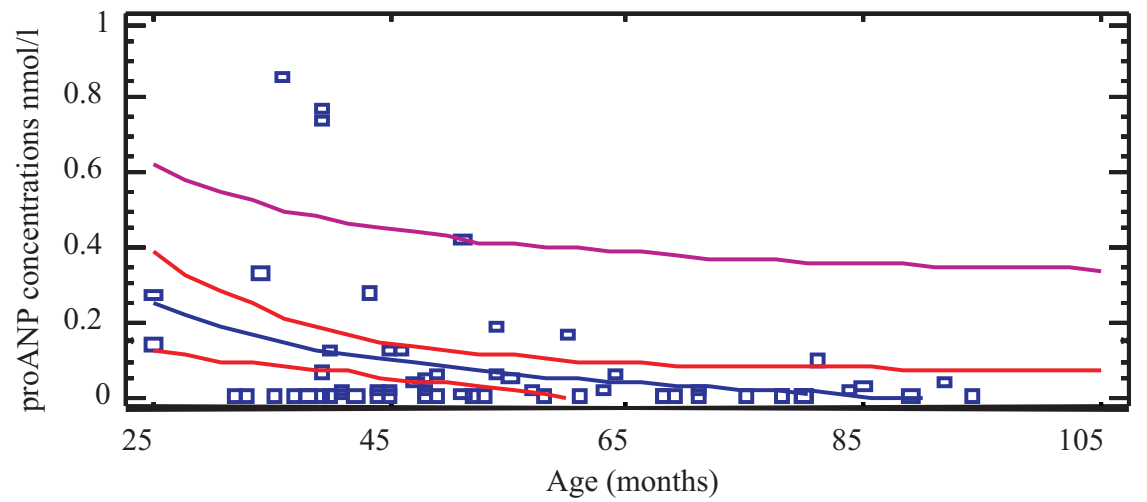

Regression Analysis - Reciprocal - X model: $\mathrm{Y}=\mathrm{a}+\mathrm{b} / \mathrm{X}$. P value $<0.01$

Fig. 4. Simple regression proANPconcentrations in the cats from group 2 and 3 vs. age (months).

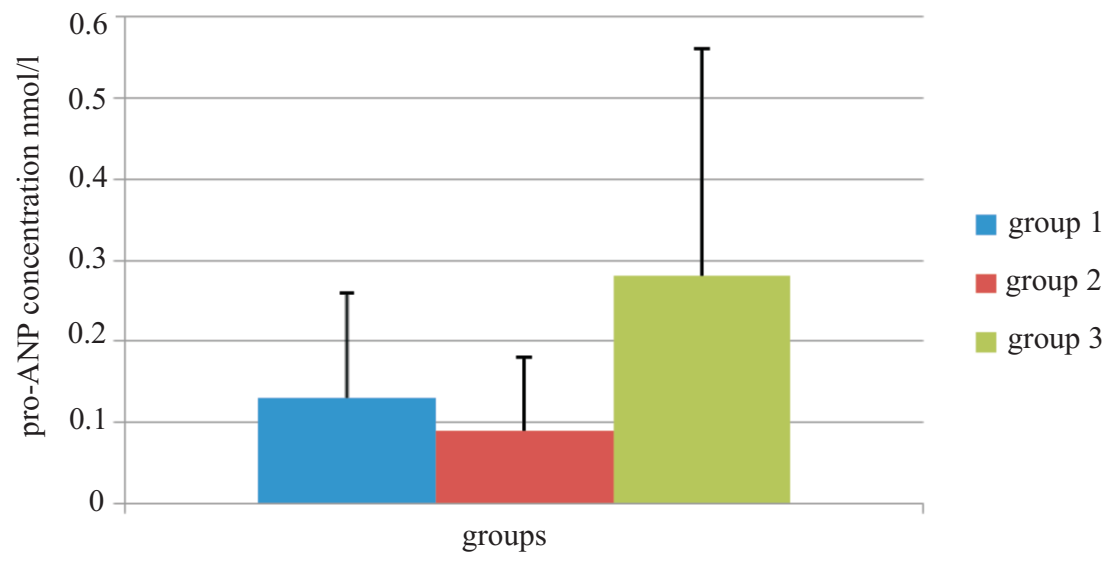

Fig. 5. Pro-ANP concentration in all 3 groups of the Maine coon cats.

from the history, while Table 5 shows results of clinical examinations. Electrocardiography did not reveal any changes in cats from groups 1, 2 or 3, including rhythm abnormalities. Atrial hypertension and hyperthyroidism were also not recognized in any of the studied cats. Mean proANP serum concentration in the healthy cats was $0.13 \pm 0.23 \mathrm{nmol} / \mathrm{l}$. There were large individual variation in proANP concentrations from 0 to $1.55 \mathrm{nmol} / \mathrm{l}$ (Fig. 1). There was no correlation between proANP levels and body weight or age of the healthy cats $(\mathrm{p}>0.05)$. The mean proANP value in cats from group 2 was $0.09 \pm 0.18 \mathrm{nmol} / \mathrm{l}$, with values ranging from $0-0.86 \mathrm{nmol} / \mathrm{l}$ (Fig. 2). There was no statistically significant difference between proANP 
levels in cats from group 1 and 2 ( $\mathrm{p}>0.05)$. ANOVA (variation) analysis showed that the level of proANP in cats from group 2 increased with increasing body weight $(\mathrm{p}<0.04, \mathrm{r}=0.304)$. The mean value of proANP in cats from group 3 was $0.28 \pm 0.60 \mathrm{nmol} / 1$ and ranged from 0-2.27 nmol/l (Fig. 3). ANOVA analysis again showed that the level of proANP in cats from group 3 increased with advancing age $(\mathrm{p}<0.01$, $r=0.5578$ ) (Fig. 4). The mean level of proANP in cats from group 3 was significantly higher than that found in cats from group 1 and $2(\mathrm{p}<0.05)$ (Fig. 5).

The level of proANP in the affected cats (group 3) was correlated with the ejection fraction $(p=0.03$, $\mathrm{r}=0.5305)$ and the left ventricular systolic diameter $(\mathrm{p}=0.05, \mathrm{r}=0.48)$. These parameters increased along with increasing levels of proANP.

No correlation was found between the parameters of left ventricular wall thickness and the serum levels of proANP in the healthy and affected cats.

\section{Discussion}

Echocardiographic measurements of the left ventricular walls, the gold standard for HCM diagnosis in cats, were used to divide the study animal population into groups because the aim of the study was to determine whether proANP can be used for early screening of subclinical HCM. The serum levels of proANP in healthy cats determined in this study were lower compared to the previously published values (Connolly et al. 2008, Zimmering et al. 2009). This could be the result of variations of values of proANP found in this study in each healthy cat, which was also observed by the previous authors. The previously published studies were performed on a small population of cats of different breeds, which could also account for the variation in proANP levels. A similar study (Pasławska 2006) in dogs has revealed large variations in proANP. To date the reason for this variation in cats and dogs has not been established. It could be a result of different times of blood sample collection (morning vs. afternoon) or other preexisting subclinical conditions not recognized during the basic clinical examination.

The differences in proANP serum levels between group 1 and 2 were statistically insignificant, which suggests that this parameter is not a good biomarker for diagnosing early/subclinical stages of HCM. The significantly higher level of proANP in cats from group 3 shows that this parameter may be used for detection of advanced stages of HCM in Maine coon cats. The results of this study are similar to those reported publications dealing with human medicine (Otterstad et al. 2002, Berger et al. 2005, Jarai et al.
2006). These studies have shown that proANP is useful for diagnosing moderate to severe cases of heart disease. In human studies, Hall et al. (2003) have shown that proANP is mostly used for heart disease with systolic dysfunction, which is a more frequent cause of left atrial enlargement and left sided heart failure. Hypertrophic cardiomyopathy in cats is associated with diastolic left ventricular dysfunction, which can often be established prior to hypertrophy with the use of advanced echocardiographic imaging such as strain/strain rate (Chetboul et al. 2006).

The present study has revealed that serum proANP may be used in the diagnosis of hypertrophic cardiomyopathy in Maine coon cats, however a significant increase was observed only in clinically affected cats in the advanced stage of the diseases. ProANP cannot be used for early detection of subclinical HCM. Because of large variations in serum proANP levels, cats with high levels of this parameter (suggesting HCM) should be assigned to echocardiographic evaluation to confirm the diagnosis.

\section{References}

Berger R, Huelsmann M, Strecker K, Moertl D, Moser P, Bojic A, Packer R (2005) Neurohormonal risk stratification for sudden death and heath owing to progressive heart failure in chronic heart failure. Eur J Clin Invest 35: 24-31.

Borgeat K, Connolly DJ, Luis Fuentes V (2015) Cardiac biomarkers in cats. J Vet Cardiol 17 (Suppl 1): 74-86.

Boswood A (2009) Biomarkers in cardiovascular disease beyond natriuretic peptides. J Vet Cardiol 11: 23-32.

Chetboul V, Sampedrano CC, Gouni V, Nicolle AP, Pouchelon JL (2006) Two-dimensional color tissue Doppler imaging detects myocardial dysfunction before occurrence of hypertrophy in a young Maine Coon cat. Vet Radiol Ultrasound 47: 295-300.

Connolly DJ, Soares Magalhaes RJ, Syme HM, Boswood A, Luis Fuentes V, Chu L, Metcalf M (2008) Circulating natriuretic peptides in cats with heart disease. J Vet Intern Med 22: 96-105.

Connolly DJ, Soares Magalhaes RJ, Fuentes VL, Boswood A, Cole G, Boag A, Syme HM (2009) Assessment of the diagnostic accuracy of circulating natriuretic peptide concentrations to distinguish between cats with cardiac and non-cardiac causes of respiratory distress. J Vet Cardiol 11 (Suppl 1): 41-50.

Connolly DJ (2010) Natriuretic peptides: the feline experience. Vet Clin North Am Small Anim Pract 40: 559-570.

Gough A, Thomas A (2004) Disease summaries. In: Gough A, Thomas A (eds) Breed predispositions to disease in dogs and cats. 2ed., Wiley Blackwell, Iowa, pp 229-230.

Hall C, Ihlen H, Bonarjee V, Dickstein K, Kjekshus J (2003) $\mathrm{N}$-terminal proatrial natriuretic peptide in primary care: relation to echocardiographic indices of cardiac function in mild to moderate cardiac disease. Int $\mathbf{J}$ Cardiol 89: 197-205. 
Jandrey K (2012) Thromboembolism: current treatment and future directions. Veterinary Focus 22: 26-31.

Jarai R, Iordanowa N, Jarai R, Raffetseder A, Woloszczuk W, Gyöngyösi M, Geyer G, Wojta J, Huber K (2005) Risk assessment in patients with unstable angina/non-ST-elevation myocardial infarction and normal N-terminal pro-brain natriuretic peptide levels by $\mathrm{N}$-terminal pro-atrial natriuretic peptide. Eur Heart J 26: $250-256$

Kittleson M, (1998) Hypertrophic Cardiomyopathy. In: Kittleson M, Kienle R (eds) Small Animal Cardiovascular Medicine. Mosby Inc, St. Louis, pp 347-360.

Kittleson MD, Meurs KM, Munro MJ, Kittleson JA, Si-Kwang L, Pion PD, Towbin JA (1999) Familial hypertrophic cardiomyopathy in maine coon cats: an animal model of human disease. Circulation 99: 3172-3180.

Kołodziejska A, Kander M, Depta A, Szweda M (2010) Structure, mechanism of action and the significance of natriuretic peptides in the diagnosis of heart disease in dogs. Życie Weterynryjne 85: 825-829.

Lalor SM, Connolly DJ, Elliott J, Syme HM (2009) Plasma concentrations of natriuretic peptides in normal cats and normotensive and hypertensive cats with chronic kidney disesase. J Vet Cardiol 11 (Supp1): 71-79.

MacLean HN, Abbott JA, Ward DJ, Huckle WR, Sisson DD, Pyle RL (2006) N- terminal atrial natriuretic peptide immunoreactivity in plasma of cats with hypertrophic cardiomyopathy. J Vet Intern Med 20: 284-289.

Menaut P, Connolly DJ, Volk A, Pace C, Luis Fuentes V, Elliott J, Syme H (2012) Circulating natriuretic peptide concentrations in hyperthyroid cats. J Small Anim Pract 53: $673-678$.

Meurs KM, Norgard MM, Kuan M, Haggström J, Kittleson M (2009) Analysis of 8 sarcomeric candidate genes for feline hypertrophic cardiomyopathy mutations in cats with hypertrophic cardiomyopathy. J Vet Intern Med 23: $840-843$.
Müller E (2006) Laboratory diagnostics in heart diseases. Weterynaria w praktyce 6: 77-79.

Otterstad JE, St John Sutton MG, Froeland GS, Holme I, Skjaerpe T, Hall C (2002) Prognostic value of two-dimensional echocardiography and $\mathrm{N}$-terminal proatrial natriuretic peptide following an acute myocardial infarction. Eur Heart J 23: 1011-1020.

Pasławska U (2006) Neurohormonal changes in dogs with heart failure secondary to chronic mitral valvedisease. Doctoral Thesis, Wrocław Agricultural Academy.

Sampedrano C, Chetboul V, Mary J, Tissier R, Abitbol M, Serres F, Gouni V, Thomas A, Pouchelon JL (2009) Prospective echocardiographic and tissue Doppler imaging screening of a population of Maine Coon cats tested for the A31P mutation in the myosin-binding protein C gene: a specific analysis of the heterozygous status. J Vet Intern Med 23: 91-99.

Trehion-Sechi E, Tissier R, Gouni V, Misbach C, Petit AM, Balouka D, Sampedrano CC, Castaignet M, Pouchelon JL, Chetboul V (2012) Comparative echocardiographic and clinical features of hypertrophic cardiomyopathy in 5 breeds of cats: a retrospective analysis of 344 cases (2001-2011). J Vet Intern Med 26: 532-541.

Ware WA (2007) Myocardial diseases of the cat. In: Ware WA (ed) Cardiovascular disease in small animal medicine. Manson Publishing, London, pp 300-308.

Zimmering TM, Meneses F, Nolte IJ, Simon D (2009) Measurement of $\mathrm{N}$-terminal proatrial natriuretic peptide in plasma of cats with and without cardiomyopathy. Am J Vet Res 70: 216-222.

Zimmering TM, Hungerbühler S, Meneses F, Nolte I, Simon $\mathrm{D}$ (2010) Evaluation of the association between plasma concentration of $\mathrm{N}$-terminal proatrial natriuretic peptide and outcome in cats with cardiomyopathy. J Am Vet Med Assoc 237: 665-672. 